\title{
Multidecadal time series of satellite-detected accumulations of cyanobacteria in the Baltic Sea
}

\author{
M. Kahru ${ }^{1,2}$ and R. Elmgren ${ }^{2}$ \\ ${ }^{1}$ Scripps Institution of Oceanography, University of California San Diego, La Jolla, CA 92093-0218, USA \\ ${ }^{2}$ Department of Ecology, Environment and Plant Sciences, Stockholm University, SE-10691, Stockholm, Sweden \\ Correspondence to: M. Kahru (mkahru@ucsd.edu)
}

Received: 26 January 2014 - Published in Biogeosciences Discuss.: 26 February 2014

Revised: 27 May 2014 - Accepted: 28 May 2014 - Published: 4 July 2014

\begin{abstract}
Cyanobacteria, primarily of the species Nodularia spumigena, form extensive surface accumulations in the Baltic Sea in July and August, ranging from diffuse flakes to dense surface scums. The area of these accumulations can reach $\sim 200000 \mathrm{~km}^{2}$. We describe the compilation of a 35 year-long time series (1979-2013) of cyanobacteria surface accumulations in the Baltic Sea using multiple satellite sensors. This appears to be one of the longest satellite-based time series in biological oceanography. The satellite algorithm is based on remote sensing reflectance of the water in the red band, a measure of turbidity. Validation of the satellite algorithm using horizontal transects from a ship of opportunity showed the strongest relationship with phycocyanin fluorescence (an indicator of cyanobacteria), followed by turbidity and then by chlorophyll $a$ fluorescence. The areal fraction with cyanobacteria accumulations (FCA) and the total accumulated area affected (TA) were used to characterize the intensity and extent of the accumulations. The fraction with cyanobacteria accumulations was calculated as the ratio of the number of detected accumulations to the number of cloud-free sea-surface views per pixel during the season (July-August). The total accumulated area affected was calculated by adding the area of pixels where accumulations were detected at least once during the season. The fraction with cyanobacteria accumulations and TA were correlated $\left(R^{2}=0.55\right)$ and both showed large interannual and decadalscale variations. The average FCA was significantly higher for the second half of the time series (13.8\%, 1997-2013) than for the first half $(8.6 \%, 1979-1996)$. However, that does not seem to represent a long-term trend but decadal-scale oscillations. Cyanobacteria accumulations were common in the 1970s and early 1980s (FCA between 11-17\%), but rare
\end{abstract}

(FCA below $4 \%$ ) during 1985-1990; they increased again starting in 1991 and particularly in 1999, reaching maxima in FCA $(\sim 25 \%)$ and TA $\left(\sim 210000 \mathrm{~km}^{2}\right)$ in 2005 and 2008. After 2008, FCA declined to more moderate levels (6-17\%). The timing of the accumulations has become earlier in the season, at a mean rate of 0.6 days per year, resulting in approximately 20 days advancement during the study period. The interannual variations in FCA are positively correlated with the concentration of chlorophyll $a$ during July-August sampled at the depth of $\sim 5 \mathrm{~m}$ by a ship of opportunity, but interannual variations in FCA are more pronounced as the coefficient of variation is over 5 times higher.

\section{Introduction}

The lifetime of a typical satellite sensor is too short to collect quantitative interannual time series of sufficient length. In the era of anthropogenic climate change it is common and justified to look for trends in environmental variables, but the observed changes in relatively short time series are most often due to decadal or interannual variability rather than long-term trends. Surface or near-surface accumulations of cyanobacteria are common in the Baltic Sea during the summer months of July and August. They are caused by massive blooms of diazotrophic cyanobacteria, primarily Nodularia spumigena but also Aphanizomenon sp. that aggregate near the surface in calm weather (Öström, 1976; Kononen, 1992; Finni et al., 2001). Cyanobacteria blooms are considered a major environmental problem in the Baltic Sea because of the loss of recreational value of the sea and beaches due to accumulations of foul-smelling, toxic cyanobacteria, and because 


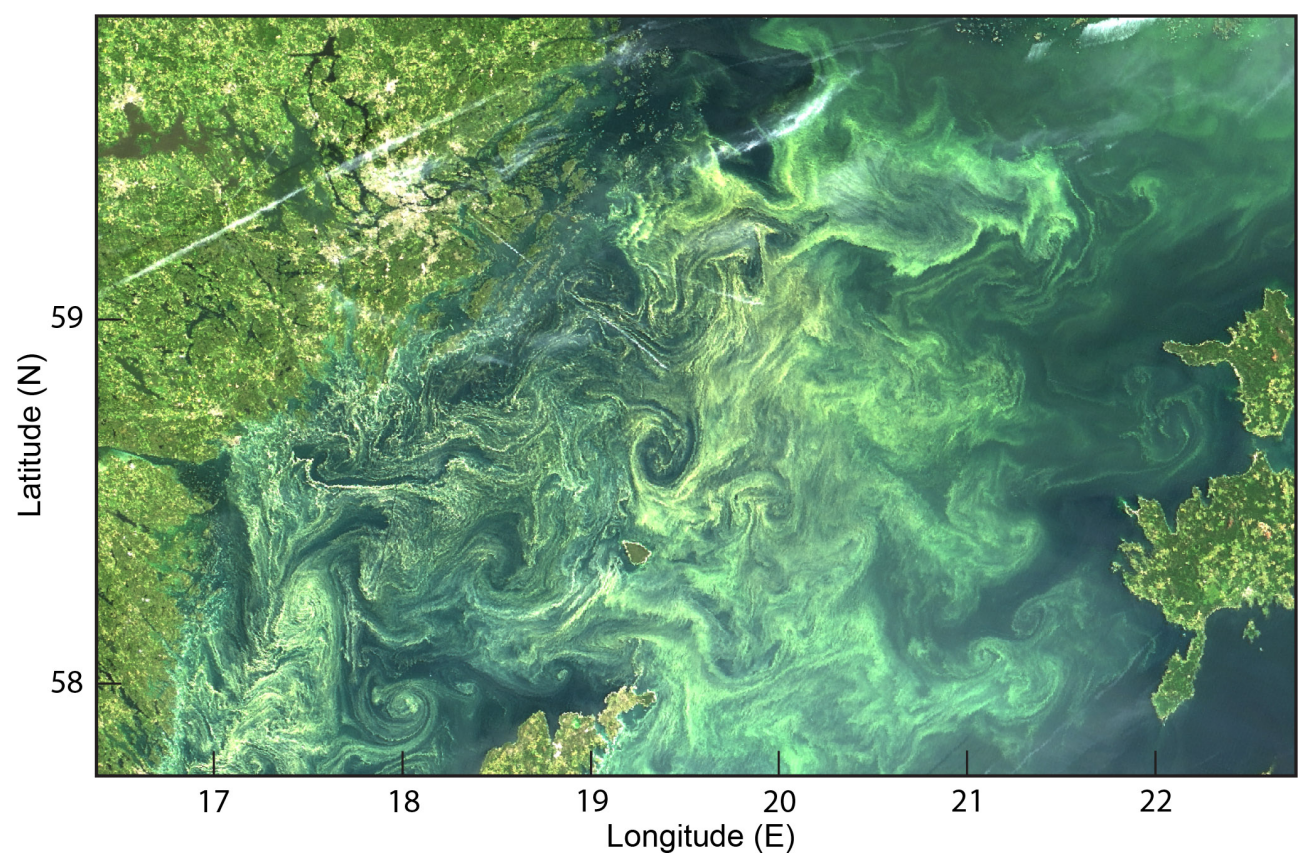

Figure 1. Cyanobacteria (primarily Nodularia spumigena) accumulations in Northern Baltic Proper on 11 July 2005 as shown on MODISTerra quasi true color image at $250 \mathrm{~m}$ resolution using bands 1 (red), 4 (green), and 3 (blue). Straight white lines are aircraft contrails.

their nitrogen fixation adds large amounts of potentially biologically available nitrogen to a eutrophicated and largely nitrogen-limited sea (Horstmann, 1975; Larsson et al., 2001). While the general factors enhancing cyanobacteria blooms such as availability of inorganic phosphorus, high surface temperature and strong near-surface stratification are well known, the specific factors determining the magnitude and distribution of the annual occurrence of these accumulations in different basins are still not understood and quantitative assessments and models allowing prediction of the accumulations are needed. Sediment records show that cyanobacteria blooms have occurred in the Baltic Sea for thousands of years (Bianchi et al., 2000). It is often assumed that their frequency and intensity have increased due to anthropogenic eutrophication (Horstmann, 1975), but such an increase has been difficult to demonstrate at the scale of the Baltic Sea, because of the intense patchiness and temporal variability of the blooms as well as due to the scarcity of reliable older measurements (Finni et al., 2001). In order to build a time series suitable for investigating long-term trends in cyanobacterial surface accumulations in the Baltic Sea and the mechanisms causing them, we have used multiple satellite sensors to create the longest possible time series of comparable observations.

While the surface accumulations consist primarily of Nodularia spumigena, other species of cyanobacteria, primarily Aphanizomenon sp., often dominate in the water column below (Hajdu et al., 2007; Rolff et al., 2007). These filamentous cyanobacteria have gas vacuoles that they can use to regulate their buoyancy (Walsby, 1994). These vacuoles are very effective backscatterers of visible light (Volten et al., 1998) and are the major contributor to the brightness that makes the accumulations visible in satellite images (Fig. 1).

Due to their temporal and spatial variability ("patchiness"), cyanobacteria surface accumulations are extremely difficult to monitor using ship-based sampling (Kutser, 2004). Their concentrations often vary by more than 2 orders of magnitude over the distance of a few meters and no suitable quantitative methods are available for reliable groundtruth measurements. Satellites sensors allow for a synoptic view over large spatial domains but visible and near-infrared sensors are limited to cloud-free periods. Automated shipborne measurements of phycocyanin fluorescence (Seppälä et al., 2007) and hyperspectral reflectance (Simis and Olsson, 2013) have the potential to provide ground-truth measurements even under cloudy conditions, but are restricted to limited horizontal transects along shipping routes. The first satellite images of the Baltic Sea showing Nodularia accumulations were acquired by the Landsat multispectral scanner (MSS) in 1975 (Öström, 1976; Horstmann, 1983). However, due to the narrow swath width and low sampling frequency the Landsat sensors produced only a few scenes per year for the whole Baltic which was insufficient for creating quantitative time series. A problem affecting all satellite data has been the lack of quantitative algorithms for estimating cyanobacteria concentrations as no suitable standard satellite products are available. The first quantitative satellite-based time series using the broadband weather sensor Advanced Very High Resolution Radiometer (AVHRR) was created in the 1990s (Kahru et al., 1994) but AVHRR data had problems separating cyanobacteria from other forms of turbidity or 
high surface reflectance. More sophisticated spectral methods that are specific to the pigment composition and other optical characteristics of cyanobacteria have been proposed (e.g., Matthews et al., 2012) but are specific to a particular set of spectral bands, e.g., those on the MEdium Resolution Imaging Spectrometer (MERIS) sensor that operated during 2003-2012. A time series based on only MERIS data would be too short to reveal multidecadal variability. Time series become more valuable the longer they become, making it essential to be able to merge data from multiple satellite sensors. We have developed simple algorithms that can be applied to various satellite sensors from the wide-band $(\sim 100 \mathrm{~nm})$ and low signal-to-noise ratio (SNR) AVHRR sensor to modern ocean color sensors with spectrally narrow $(\sim 10 \mathrm{~nm}$ ) bands and high SNR. The aim of this study was to create a quantitative multidecadal time series of cyanobacteria accumulation characteristics in the Baltic Sea using those compatible algorithms.

\section{Data and methods}

\subsection{Satellite data}

A summary of the various satellite sensors that have been used to detect cyanobacteria from space is in Table 1 . The first ocean color sensor Coastal Zone Color Scanner (CZCS) (Hovis et al., 1980) was an experimental sensor operated by NASA during 1978-1986 and was turned on only intermittently due to its limited recording capacity. A reasonable number of CZCS scenes from the Baltic Sea are available for the July-August season during 19791984 (Table 2). Coastal Zone Color Scanner data were downloaded as Level-2 files from NASA's ocean color web (http://oceancolor.gsfc.nasa.gov/).

A broadband weather sensor, named Advanced Very High Resolution Radiometer (AVHRR), has been flown on a series of NOAA polar orbiting satellites and data since 1979 are available (Kidwell, 1995). The advantages of AVHRR are its wide swath (over $2000 \mathrm{~km}$ ), frequent coverage (up to several passes per day), and availability over a long period of time. However, compared to specialized ocean color sensors, AVHRR has only two broadband spectral channels in the visible $(0.58-0.68 \mu \mathrm{m})$ and near infrared $(0.72-1.10 \mu \mathrm{m})$ ranges with low sensitivity and poor calibration accuracy. This makes atmospheric correction difficult and limits its capability to distinguish algal blooms near and at the surface from suspended sediments, certain types of clouds as well as bottom reflection in shallow areas. In spite of these limitations, AVHRR data has been used to detect highly reflective blooms such as coccolithophores (Groom and Holligan, 1987) and cyanobacteria in the Baltic (Kahru et al., 1993, 1994, 2000; Kahru, 1997). We used AVHRR data recorded at multiple locations, including Stockholm University. The most complete archive of AVHRR over Europe since 1979 is available from the Dundee Satellite Receiving Station (http://www.sat.dundee.ac.uk/). For detecting cyanobacteria we used only satellite passes near local noon (10:00-14:00 local time), as atmospheric scattering and absorption mask the relatively weak signal from the water surface at low sun elevation. While data from AVHRR sensors were transmitted daily, due to various failures we have less than the maximum number of daily AVHRR data sets during the July-August period of the early years (Table 2).

Data from modern ocean color sensors are available daily with multiple passes per day and all Level-2 data files from SeaWiFS, MODIS-Aqua (MODISA), MODIS-Terra (MODIST) and VIIRS sensors of the summer months from June to August were downloaded from NASA's ocean color archive (http://oceancolor.gsfc.nasa.gov/). The total number of files (Table 2) depends on the number and type of sensors. SeaWiFS was the only ocean color sensor operational in the 1998-1999 period. After that period (2000 and later) data from multiple ocean color sensors were available simultaneously. SeaWiFS Level-2 data sets are distributed in a single file whereas MODISA, MODIST and VIIRS data are broken into multiple granules and therefore the number of files is higher. Between 2005 and 2010 SeaWiFS data were only available at the low $(4 \mathrm{~km})$ resolution (GAC) mode and were not used. We combine multiple satellite passes and multiple files per day and show the number of days in the JulyAugust period with useable data ("N of valid days") in Table 2 . Scenes that were completely cloudy or produced no valid water surface data were excluded.

While the MODIS sensors on Terra and Aqua have bands with $250 \mathrm{~m}$ and $500 \mathrm{~m}$ resolution (e.g., Fig. 1), these bands typically have lower signal-to-noise ratios. For compatibility between different sensors, all satellite data used in the quantitative analysis in this work had approximately $1 \mathrm{~km}$ spatial resolution. All satellite data were registered to a standard equal area map with an Albers conic projection with $1 \mathrm{~km}^{2}$ pixel size (Fig. 2). Since cyanobacteria blooms are not known to occur in the Bothnian Bay, this northernmost part of the Baltic Sea was excluded from all maps and calculations. Coastal zones shallower than $30 \mathrm{~m}$ and other turbid areas were also excluded (more below).

While there is better data coverage from 1998 and onwards (Fig. 3), even the approximately 40-50 days of combined AVHRR and CZCS coverage in the early years of 1979-1986 are sufficient for quantitative seasonal estimates as the accumulations are relatively consistent from day to day. The detected total area approaches a plateau after about one satellite image per bloom day (Fig. 3.9 in Kahru, 1997), and the fraction of cyanobacteria accumulations (details below) are normalized to the number of clear (valid) viewings. 
Table 1. Characteristics of satellite sensors used to detect cyanobacteria accumulations in the Baltic Sea.

\begin{tabular}{|c|c|c|c|c|c|c|}
\hline Sensor & Satellite & Agency & $\begin{array}{r}\text { Center wavelength } \\
\text { of the red band } \\
\text { (width) } \mathrm{nm},\end{array}$ & $\begin{array}{r}\text { Spatial, } \\
\text { resolution } \\
\mathrm{m}\end{array}$ & $\begin{array}{r}\text { Temporal resolution, } \\
\text { resolution } \\
\text { days }\end{array}$ & $\begin{array}{r}\text { Signal-to-noise ratio } \\
\text { of the red } \\
\text { band }\end{array}$ \\
\hline MSS & Landsat 2 (ERTS-B) & NASA/USGS & $650(100)$ & 83 & 18 & 40 \\
\hline $\mathrm{TM}$ & Landsat 5 & NASA/USGS & $660(60)$ & 30 & 16 & 50 \\
\hline CZCS & Nimbus-7 & NASA & $670(20)$ & 825 & irregular & 100 \\
\hline AVHRR & NOAA-X & NOAA & $630(100)$ & 1100 & $<1$ & 3 \\
\hline SeaWiFS & Orbview-2 & NASA & $670(20)$ & 1100 & $\sim 2$ & 390 \\
\hline MODIS & Terra & NASA & $667(10)$ & $250 / 500 / 1000$ & $\sim 2$ & 910 \\
\hline MODIS & Aqua & NASA & $667(10)$ & $250 / 500 / 1000$ & $\sim 2$ & 910 \\
\hline MERIS & ENVISAT & ESA & $665(10)$ & $300 / 1200$ & $\sim 3$ & 883 \\
\hline VIIRS & NPP & NOAA/NASA & $671(20)$ & $370 / 740$ & $\sim 2$ & 750 \\
\hline
\end{tabular}
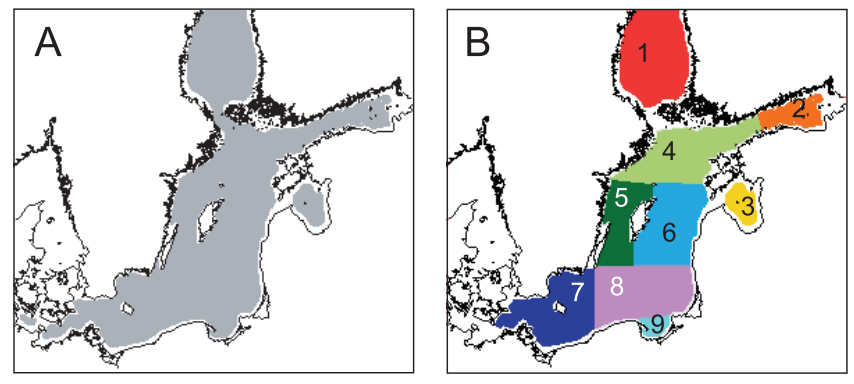

Figure 2. Study areas in the Baltic Sea. (A) The area considered (grey) in mapping cyanobacteria blooms excludes near-shore areas with potentially high turbidity (white, $19.5 \%$ of the total sea area). (B) Partition into nine separate basins: Bothnian Sea (BS, 1), Gulf of Finland (GF, 2), Gulf of Riga (GR, 3), Northern Baltic Proper (NBP, 4), Western Gotland Basin (WGB, 5), Eastern Gotland Basin (EGB, 6), south-southwestern Baltic Proper (SWBP, 7), south-southeastern Baltic Proper (SEBP, 8), Bay of Gdansk (BG, 9); Kahru et al., 2007.

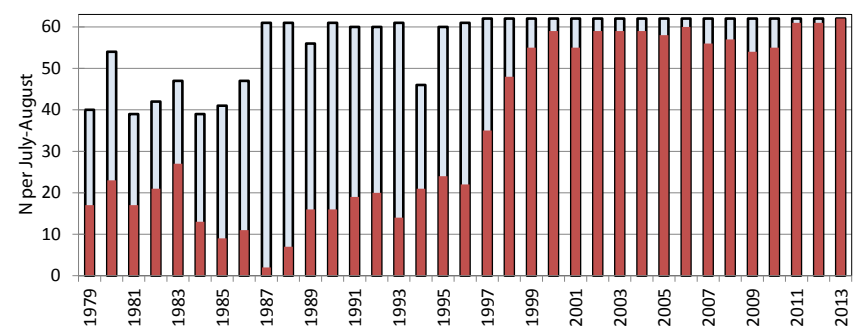

Figure 3. Number of daily satellite data sets used in the analysis of the July-August seasons of 1979-2013. Column height shows the total number of daily data sets with valid ocean data, the red filled part shows the number of daily data sets with detected accumulations.

\subsection{Methods of detecting cyanobacteria accumulations}

\subsubsection{AVHRR}

The low sensitivity and poor calibration accuracy of AVHRR's two broadband spectral channels make accurate atmospheric correction difficult. Even with the best available calibration coefficients, atmospheric correction often resulted in physically impossible negative values of the waterleaving radiance (Stumpf and Fryer, 1997). We therefore used the standard AVHRR band 1 albedo (Kidwell, 1995) to detect cyanobacteria. The supervised classification algorithm as applied to AVHRR data has been described previously (Kahru et al., 1994; Kahru, 1997). The range of band 1 albedo of the accumulations was determined empirically and varied between 2.3 and $4 \%$, with lower values classified as water and higher values as clouds. However, these values were used as guidance and had to be empirically adjusted for some scenes. The surface distribution of cyanobacteria accumulations has a very characteristic spatial texture and patterns of swirls, eddies and filaments (Fig. 1) that are useful in separating the accumulations from clouds, fog and aircraft contrails. Areas with such high spatial texture were considered cyanobacteria accumulations. Multiple thresholdings and differences in the visible, near infrared and thermal channels were used to eliminate pixel areas with similar albedo. Data in the near-infrared band 2 and the two thermal infrared bands, $4(10.4-11.0 \mu \mathrm{m})$ and $5(11.6-12.2 \mu \mathrm{m})$, were used to screen clouds, haze, land and error pixels. Pixels with band 2 albedo values exceeding the corresponding band 1 albedo by $0.2 \%$ were classified as land or considered an error. Pixels with band 4 and band 5 differences greater than $2{ }^{\circ} \mathrm{C}$ were designated as clouds. Finally, visual inspection and editing were used to eliminate pixels erroneously marked as accumulations due to variable clouds and sediment-rich coastal areas. As cyanobacteria accumulations are usually present in the same location for more than one day, while clouds and other atmospheric effects are more transient, sequences of images were checked for consistency 
Table 2. Number and type of daily detected ("turbid") and useable ("valid") satellite data sets, mean fraction of cyanobacteria accumulations (FCA \%), total area covered by accumulations (TA) over the Baltic Sea during the July-August period, and the sensors used in the analysis. For each sensor the number of daily scenes is given in brackets or the combined number of scenes for ocean color sensors.

\begin{tabular}{|c|c|c|c|c|c|}
\hline Year & $\begin{array}{r}N \text { of } \\
\text { turbid } \\
\text { days }\end{array}$ & $\begin{array}{l}N \text { of } \\
\text { valid } \\
\text { days }\end{array}$ & FCA $\%$ & $\begin{array}{r}\text { TA, } \\
1000 \\
\mathrm{~km}^{2}\end{array}$ & Sensor \\
\hline 1979 & 17 & 40 & 11.2 & 57 & CZCS, AVHRR \\
\hline 1980 & 23 & 54 & 11.7 & 59 & CZCS, AVHRR \\
\hline 1981 & 17 & 39 & 16.8 & 91 & CZCS, AVHRR \\
\hline 1982 & 21 & 42 & 12.9 & 69 & CZCS, AVHRR \\
\hline 1983 & 27 & 47 & 12.3 & 78 & CZCS, AVHRR \\
\hline 1984 & 13 & 39 & 17.0 & 86 & CZCS, AVHRR \\
\hline 1985 & 9 & 41 & 1.1 & 3 & AVHRR \\
\hline 1986 & 11 & 47 & 3.3 & 14 & AVHRR \\
\hline 1987 & 2 & 61 & 0.4 & 1 & AVHRR \\
\hline 1988 & 7 & 61 & 2.1 & 8 & AVHRR \\
\hline 1989 & 16 & 56 & 3.9 & 23 & AVHRR \\
\hline 1990 & 16 & 61 & 3.8 & 26 & AVHRR \\
\hline 1991 & 19 & 60 & 10.2 & 74 & AVHRR \\
\hline 1992 & 20 & 60 & 13.1 & 60 & AVHRR \\
\hline 1993 & 14 & 61 & 6.9 & 39 & AVHRR \\
\hline 1994 & 21 & 46 & 14.3 & 103 & AVHRR \\
\hline 1995 & 24 & 60 & 4.3 & 40 & AVHRR \\
\hline 1996 & 22 & 61 & 2.3 & 21 & AVHRR \\
\hline 1997 & 35 & 62 & 16.0 & 127 & AVHRR \\
\hline 1998 & 48 & 62 & 5.9 & 129 & SeaWiFS, AVHRR \\
\hline 1999 & 55 & 62 & 21.6 & 209 & SeaWiFS, AVHRR \\
\hline 2000 & 59 & 62 & 13.1 & 178 & SeaWiFS, MODIST \\
\hline 2001 & 55 & 62 & 12.4 & 139 & SeaWiFS, MODIST \\
\hline 2002 & 59 & 62 & 14.5 & 176 & SeaWiFS, MODISA, MODIST \\
\hline 2003 & 59 & 62 & 17.9 & 176 & SeaWiFS, MODISA, MODIST \\
\hline 2004 & 59 & 62 & 9.5 & 155 & SeaWiFS, MODISA, MODIST \\
\hline 2005 & 58 & 62 & 25.0 & 183 & MODISA, MODIST \\
\hline 2006 & 60 & 62 & 14.8 & 174 & MODISA, MODIST \\
\hline 2007 & 56 & 62 & 7.1 & 110 & MODISA, MODIST \\
\hline 2008 & 57 & 62 & 25.5 & 212 & MODISA, MODIST \\
\hline 2009 & 54 & 62 & 6.1 & 160 & MODISA, MODIST \\
\hline 2010 & 55 & 62 & 10.7 & 143 & MODISA, MODIST \\
\hline 2011 & 61 & 62 & 16.5 & 186 & MODISA, MODIST \\
\hline 2012 & 61 & 62 & 9.1 & 155 & MODISA, MODIST, VIIRS \\
\hline 2013 & 62 & 62 & 11.1 & 165 & MODISA, MODIST, VIIRS \\
\hline 1979- & Total & Total & Mean & Mean & \\
\hline 2013 & 1252 & 1990 & 11.0 & 104 & \\
\hline
\end{tabular}

of the detected accumulations over several images and suspected classification errors were manually deleted. When some of the AVHRR data were reprocessed during 20122013 for comparing with modern ocean color data, the tests involving infrared bands 4 and 5 were skipped as it was determined that these tests did not contribute much to the outcome. This simplification did not make a significant difference as valid ocean areas were still determined as band 1 albedo less than $4 \%$ and the cyanobacteria accumulations were determined visually by their high reflectance and characteristic spatial patterns. While these methods cannot un- equivocally separate isolated accumulations from certain thin clouds, floating pine pollen or suspended sediments in shallow areas or near the coast, large-scale cyanobacteria accumulations, particularly those of Nodularia, mainly occur offshore (e.g., Wasmund, 1997), away from the coast and are clearly detected. Near-shore areas with depths less than $30 \mathrm{~m}$ and with frequent turbidity were eliminated using a fixed map (Fig. 2) as reliable separation of accumulations from other forms of turbidity was not possible in coastal areas. A sample AVHRR image showing extensive cyanobacteria accumulations in band 1 albedo and the corresponding maps of 


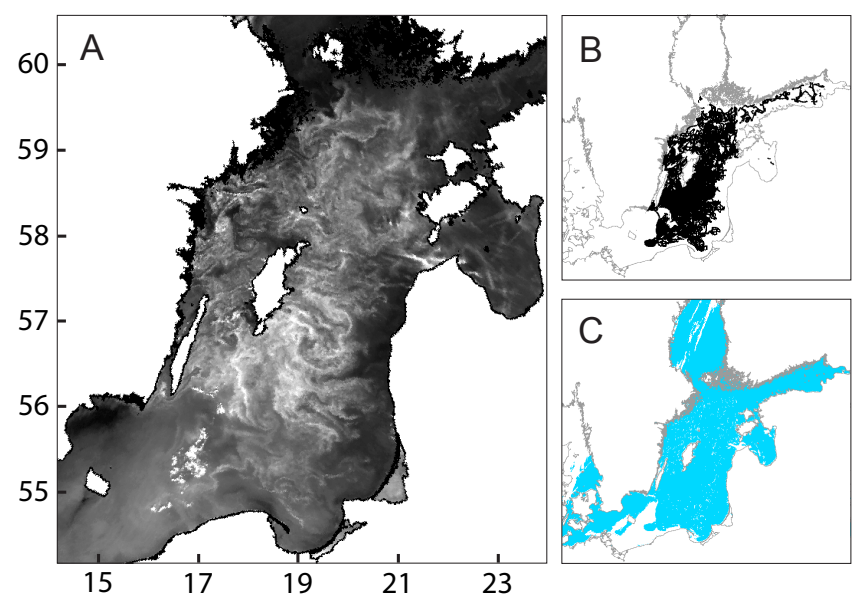

Figure 4. Example of cyanobacteria detection on AVHRR imagery of central Baltic Sea on 10 July 2005. (A) Grayscale image of band 1 albedo (bright tones correspond to higher albedo, dark tones to lower albedo). (B) Detected cyanobacteria accumulations (black). (C) Valid ocean areas (blue).

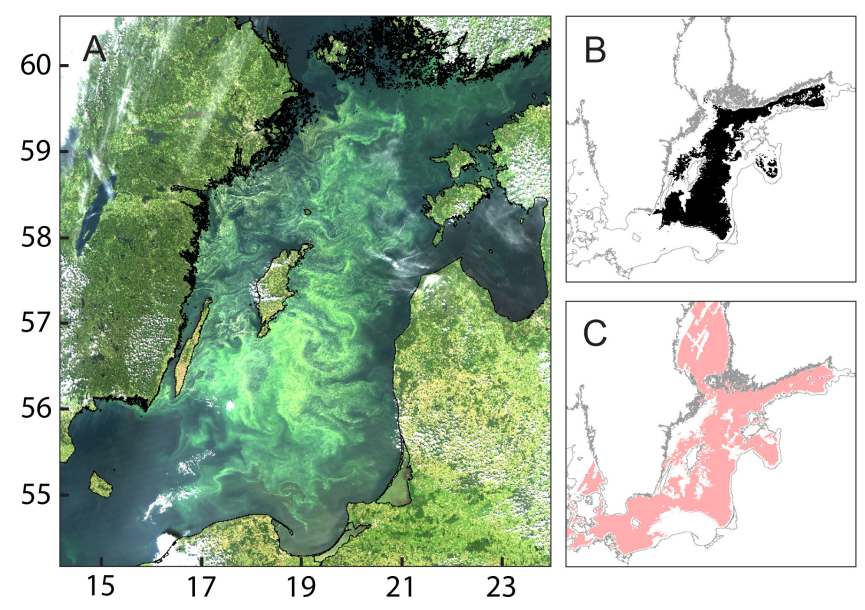

Figure 5. Example of cyanobacteria detection on MODIS-Aqua imagery of central Baltic Sea on 10 July 2005. (A) Quasi truecolor image using bands 1 (red), 3 (blue), 4 (green). Small clouds (bright white) can be seen over both land and the sea. (B) Detected cyanobacteria accumulations (black). (C) Valid ocean areas (pink).

detected accumulations as well as valid ocean area are shown in Fig. 4. A comparison of detecting the same accumulations (10 July and 11 July 2005) with the more accurate ocean color imagery (MODIS-Aqua and MODIS-Terra) is shown in Figs. 5 and 6.

\subsubsection{Ocean color sensors}

The detection of cyanobacteria accumulations in the open Baltic Sea is based on the assumption that highly reflective areas with a characteristic spatial structure occurring during July-August are caused by accumulations of cyanobacteria. The methods applied to ocean color sensors such as Sea-

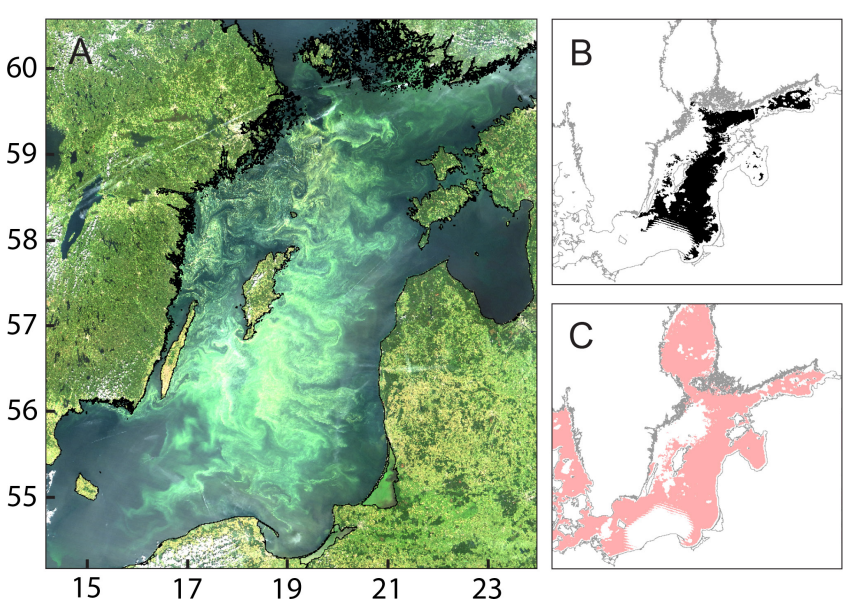

Figure 6. Example of cyanobacteria detection on MODIS-Terra imagery of central Baltic Sea on 11 July 2005. (A) Quasi true-color image using bands 1 (red), 3 (blue), 4 (green). (B) Detected cyanobacteria accumulations (black). (C) Valid ocean areas (pink).

WiFS, MODISA, MODIST and VIIRS as well as the early CZCS were essentially the same as described in Kahru et al. (2007). After the 2009 reprocessing, the standard NASA ocean color output is expressed as remote sensing reflectance $(R r s)$ instead of the formerly used normalized water-leaving radiance $(n L w)$. The conversion between $R r s$ and $n L w$ is straightforward: $n L w(\lambda)=$ solar_irradiance $(\lambda) \times \operatorname{Rrs}(\lambda)$. The semi-automated method of detection of cyanobacteria accumulations is based on high reflectance of the approximately $670 \mathrm{~nm}$ band (Rrs667 for MODISA and MODIST, Rrs670 for SeaWiFS, Rrs671 for VIIRS). Thresholding of the Rrs of the red band is part of the standard NASA Level-2 processing and the Level-2 flag TURBIDW ("turbid water") is set if $\operatorname{Rrs} 670>0.012 \mathrm{sr}^{-1}$ (http://oceancolor.gsfc.nasa.gov/ VALIDATION/flags.html). This condition is required but not sufficient for a pixel to be classified as an accumulation pixel. High reflectance in the $670 \mathrm{~nm}$ band is caused by strong backscatter of particles that are either in the water column near the surface or directly at the surface (surface scum). Both near-surface and surface backscattering is indicative of high cyanobacteria concentrations. High water reflectance at $670 \mathrm{~nm}$ can also be caused by various other particles in the water column, i.e., turbidity, such as organic and inorganic particles in river runoff or re-suspended particles from the bottom, or by other particles floating at the surface (such as pine pollen). However, such other causes of turbidity or high backscattering are rare in the open Baltic Sea in July and August. Coastal zones and shallow areas of known high reflectance are excluded by using a spatial mask (Fig. 2). For detecting cyanobacteria accumulations we also require that the flag MAXAERITER (maximum aerosol iteration) is off as this flag is set if there is a problem in atmospheric correction that often occurs near cloud edges. Using the MAXAERITER flag eliminates many false positives. 
A pixel is classified as a valid ocean pixel only if none of the following flags are set: ATMFAIL, LAND, HIGLINT, HILT, HISATZEN, STRAYLIGHT, CLDICE, HISOLZEN, LOWLW, CHLFAIL, MAXAERITER and ATMWARN. The primary flag here is CLDICE, which indicates high reflectance due to clouds as ice is not possible in the JulyAugust imagery. A pixel is classified as an accumulation if (1) it is a valid ocean pixel and (2) if it has the high turbidity flag set. All Level-2 (i.e., data processed to remote sensing reflectance but unmapped) satellite passes are visually evaluating using images of Rrs555 (SeaWiFS) or Rrs547 (MODISA and MODIST) or Rrs551 (VIIRS). Atmospheric correction failure sometimes occurred in the middle of the densest cyanobacteria accumulations and was caused by dense surface scum. These areas in the middle of accumulations were clearly identifiable and were manually filled with the turbid water class. They always represented a small $(<5 \%)$ fraction of the total area of detected accumulations.

Sometimes turbid plumes originating from the coast can extend into the Baltic Sea area used in our calculations, i.e., outside of the coastal zone that is eliminated from the analysis. These plumes are almost always clearly originating from the coast and have been eliminated by visual inspection. Some manual elimination of false positives was also needed for SeaWiFS data, particularly along cloud edges. SeaWiFS data have lower signal-to-noise ratio than MODIS data and therefore higher levels of noise variance (Hu et al., 2013). Some areas, e.g., the Bay of Gdansk and the Gulf of Riga, are often turbid (e.g., Liblik and Lips, 2011) and the detection of cyanobacteria accumulations there is sometimes ambiguous. However, obvious cyanobacteria accumulations in these areas are distinguishable by their spatial structure. In these areas accumulations were confirmed only if the adjacent areas also showed accumulations. A comparison of the results of applying the algorithms described in this section to 10-11 July 2005 images of MODISA and MODIST (Figs. 5, 6) shows good agreement between those two as well as AVHRR (Fig. 4). The CZCS was less sensitive than SeaWiFS and MODIS, and the TURBIDW flag was almost never set for valid ocean pixels. We therefore used the high reflectance determined as $n L w 555>0.8 \mathrm{~mW} \mathrm{~cm}{ }^{-2} \mu \mathrm{m}^{-1} \mathrm{sr}^{-1}$ with characteristic spatial patterns to detect likely cyanobacteria accumulations.

\subsection{Routine processing of satellite data}

Multiple satellite passes (Level-2 unmapped data sets) that were classified into valid ocean and turbid classes were registered to a standard map with an Albers conic equal area projection with a $1 \mathrm{~km}^{2}$ pixel size (Fig. 2) and composited into daily maps of valid ocean and turbid ocean classes. Those daily maps from individual satellite sensors were then composited into merged daily maps of valid and turbid classes. Obviously, a pixel needs to be a valid ocean pixel in order to be classified as a turbid ocean pixel. For each pixel the counts
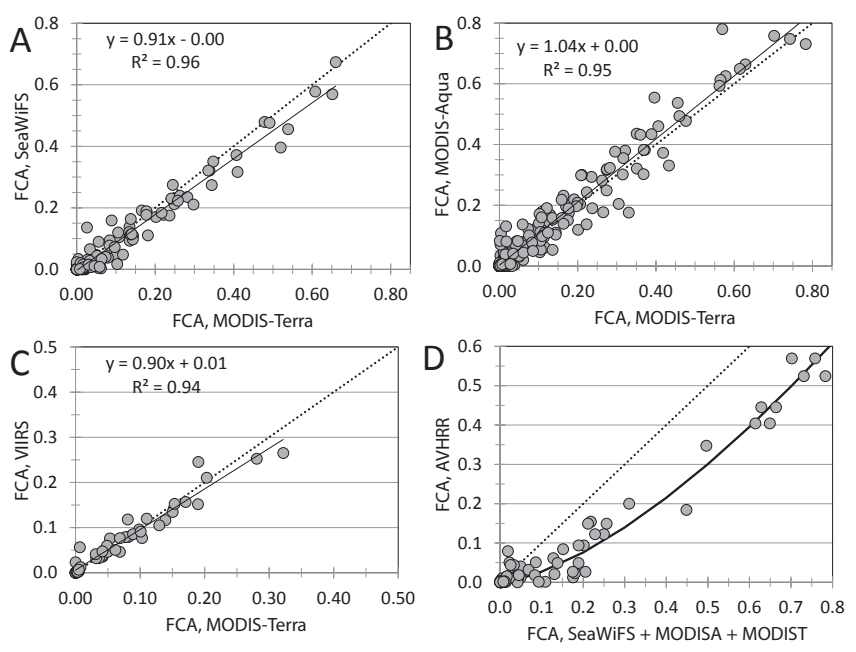

Figure 7. FCA derived with one sensor versus FCA derived with another sensor in nine areas of the Baltic. (A) SeaWiFS versus MODIST, $N=135$, June-August 2000-2004. (B) MODISA versus MODIST, $N=243$, June-August 2002-2013. (C) VIIRS versus MODIST, $N=54$, June-August 2012-2013. (D) AVHRR versus SeaWiFS (1998, 1999), MODISA (2005) and MODIST (2000, 2005), $N=108$. The dotted line is the one-to-one line and the solid line is the estimated linear regression line. For AVHRR the power function $\mathrm{FCA}_{\mathrm{N}}=0.85 \times \mathrm{FCA}^{1.5}$ was used to convert $\mathrm{FCA}_{\mathrm{N}}$ to FCA.

of valid and turbid classes were accumulated over five-day, one-month and two-month periods. From these counts the fraction of cyanobacteria accumulations (FCA) was calculated as the ratio of the number of counts: $N$ (turbid) $/ N$ (valid). The fraction of cyanobacteria accumulations shows the fraction of days when cyanobacteria accumulation was detected per cloud-free daily measurements. Another metric that has been used in the past, the total area (TA) or cumulative area, shows the total area where accumulations were detected at least once during the whole season (June-August). As the area of each pixel in our standard map is $1 \mathrm{~km}^{2}$, TA in $\mathrm{km}^{2}$ is equivalent to the number of detected turbid pixels in the overall (seasonal) composite of turbid areas. Nodularia blooms producing surface accumulations typically occur from the end of June to the end of August (Kononen, 1992; Kahru et al., 1994; Wasmund, 1997). The monthly mean FCA for June is normally very low. We therefore used the July to August mean FCA as the indicator of the annual intensity of the accumulations.

A total of 1990 daily data sets (Table 2), typically merged from multiple sensors, were used over the July-August period of 1979-2013 which makes an average of over 57 days per year (out of the maximum of 62 days per July-August). The number of individual scenes per day could be further increased by using the 10 years of MERIS data (2002-2011 for the July-August period) and the full-resolution SeaWiFS data for 2005-2010. However, these data will not increase 
the number of daily valid data sets as these years are already well covered by other sensors.

\subsection{Comparison between the outputs of different sensors}

Satellite sensors differ in overpass times, orbits and swath widths, view and solar angles, as well as spectral bands and sensitivities (e.g., signal-to-noise ratio, SNR). Their sensitivity can change over time and NASA therefore continuously monitors, and intermittently recalibrates and reprocesses all previously collected data. Variations between FCA of different sensors are therefore to be expected, particularly due to differences in overpass times and in the surface areas obscured by clouds. In order to evaluate the errors and variability of our FCA estimates, we compared the mean monthly FCAs obtained by multiple simultaneous sensors in nine different areas of the Baltic Sea (Fig. 2). Larger random variations are expected for smaller areas, e.g., the Bay of Gdansk.

SeaWiFS, MODIST, MODISA and VIIRS have all overlapped temporally with at least one other sensor. We used FCA obtained from MODIST $\left(\mathrm{FCA}_{\mathrm{T}}\right.$ ) as the common ordinate variable in comparisons with all other sensors (Fig. 7). The results showed that FCA values obtained with temporally overlapping ocean color sensors (SeaWiFS, MODIST, MODISA and VIIRS) were all highly correlated $\left(R^{2} \sim 0.94\right.$ $0.96)$ and had a linear regression with an intercept that was not significantly different from zero and a slope that was close to 1.0. These conclusions were also confirmed separately for individual years when FCA could be compared for two sensors. The only exception was year 2011 when FCA $_{T}$ was approximately 1.3 times higher than FCA obtained with MODISA $\left(\mathrm{FCA}_{\mathrm{T}}=1.316 \times \mathrm{FCA}_{\mathrm{A}}+0.0015, R^{2}=0.9413\right.$, $N=27$ ). The reason for this anomaly is not clear but it is possible that the slightly higher $\mathrm{FCA}_{\mathrm{T}}$ was caused by the higher noise level and less accurate calibration of MODIST. Another factor that may influence the difference between sensors is the overpass time. The MODIS-Terra overpass was at approximately 10:30 LT and the MODIS-Aqua overpass at approximately 13:30 LT. During calm weather it might be expected that more accumulations would develop by the afternoon, but currently we have not confirmed any systematic influence of the overpass time on FCA. The fraction of cyanobacteria accumulations derived with the new VIIRS sensor corresponds well to FCA derived with the other sensors for the two years (2012 and 2013) available for comparison (Fig. 7c).

The error of the monthly FCA as determined by a satellite sensor can be estimated as (1) the mean absolute difference and (2) the median absolute difference between FCA values of different sensors. For MODISA, MODIST and VIIRS, the mean absolute differences were 1.1-1.9\% FCA and the median absolute differences were between 0.4 and $0.6 \%$ FCA. For SeaWiFS, the respective errors were slightly higher (2.0 and $1.1 \%$ FCA, respectively).
Considering the highly variable nature of the accumulations and the variable orbits covering the Baltic Sea at different times of the day, we concluded that the differences between FCA values obtained by different ocean color sensors were insignificant and therefore the results of individual sensors could be merged to estimate FCA.

Larger differences in FCA are expected when comparing the "new" ocean color sensors with the "old" and less accurate AVHRR sensor. Due to its lower sensitivity, AVHRR is expected to be less effective in detecting accumulations that are small or barely above the detection limit of the more sensitive ocean color sensors. We compared FCAs from the AVHRR on NOAA satellites $\left(\mathrm{FCA}_{\mathrm{N}}\right)$ with FCAs from SeaWiFS (1998, 1998), MODISA (2005) and MODIST (2000, 2005) in nine areas of the Baltic in July and August. The overall linear regression between FCA $\mathrm{N}_{\mathrm{N}}$ and FCA has an $R^{2}$ of 0.82 , which increased to 0.94 when excluding the often turbid areas of Gdansk Bay, Gulf of Riga and eastern Gulf of Finland where detection is often ambiguous. An underestimation by $\mathrm{FCA}_{\mathrm{N}}$ is particularly evident at low FCA levels. We approximated this relationship with a power function $\mathrm{FCA}_{\mathrm{N}}=0.95 \times \mathrm{FCA}^{1.5}$ which models the lower detection efficiency at low FCA and the relatively good detection efficiency at high FCA. It appeared that the dense and large-scale accumulations were well detected by AVHRR, and it produced FCA values that are only slightly lower than FCAs determined simultaneously with ocean color sensors (Fig. 7d). We then used the inversion of the power function to convert $\mathrm{FCA}_{\mathrm{N}}$ to FCA. We concluded that after applying the conversion, FCA determined with AVHRR was comparable to FCA determined with other sensors, particularly for the intense and large-scale accumulations that mattered most in detecting the interannual variability.

\subsection{Horizontal transects measured on ships of opportunity}

For validating the daily images of satellite-detected cyanobacteria accumulations we used horizontal transects obtained from the Algaline (Rantajärvi, 2003) ships of opportunity instrumented with a system measuring, among others, chlorophyll $a(\mathrm{Chl} a$ ) fluorescence, phycocyanin (PC) fluorescence and turbidity (Seppälä et al., 2007). The flowthrough instrument system was installed on a ferryboat commuting between Helsinki (Finland) and Travemünde (Germany) and sampled from flow-through water pumped from approximately $5 \mathrm{~m}$ depth. For this analysis we used data collected during 15 transects in July 2010 and provided by J. Seppälä (Finnish Environment Institute, SYKE). The measured relative voltages of PC fluorescence, Chl $a$ fluorescence and turbidity were normalized between the respective minima and maxima and converted to a scale from 0-100. For each ship measurement, the nearest satellite pixel was found in the corresponding daily merged image of detected accumulations, and valid pixels were averaged in the $5 \times 5$ 
pixel neighborhood centered at the nearest satellite pixel. A pixel with detected accumulation was assumed to have a value of 1 and a valid pixel with no detected accumulation to have a value of 0 . This averaging was performed to compensate for the possible advection of the accumulations during the temporal shift between satellite passes and ship measurements (up to $24 \mathrm{~h}$ ).

\section{Results}

\subsection{Validation of satellite detection of cyanobacteria accumulations with horizontal transects measured on ships of opportunity}

Figure 8 shows a comparison between four ship transects of phycocyanin (PC) fluorescence and satellite detection of cyanobacteria accumulations on single day images in July 2010. The accumulations started to be detectable in the beginning of July in the Bay of Gdansk (near $19^{\circ} \mathrm{E}$ longitude), and the narrow patches of accumulations were lined up very well on both the ship transect and on the satellite map (Fig. 8a-b). By July 10, the accumulations were widespread both in the Northern and Southern Baltic Proper (Fig. 8c-d). The narrow tongue of accumulations just outside of the Bay of Gdansk was well detected by both measurements. In the southwestern Baltic, the band of increased PC fluorescence $\left(14-15^{\circ} \mathrm{E}\right)$ was associated with a few scattered, detected pixels of accumulations and the corresponding average cyanobacteria score was therefore relatively low. On 12 and 20 July, massive accumulations covered both Northern and Southern Baltic Proper, but the ship track was not optimal for detecting particularly the southern accumulations. The ship transects on 12 July (west of the island of Gotland, Fig. 8e-f) and on 20 July (east of Gotland, Fig. 8gh) were both along the edge of the major area of accumulations in the Southern Baltic Proper, and that probably caused a large part of the variability in the average cyanobacteria score there. Narrow strips of increased PC fluorescence corresponded well to detected cyanobacteria, but we could not detect a common threshold of PC fluorescence above which the surface accumulations could be detected by our satellite algorithm. That was expected as the correspondence between ship measurements at $5 \mathrm{~m}$ depth and satellite measurements of the surface layer depends on the vertical distribution of cyanobacteria and the depth of the top layer within which the cyanobacteria flakes (aggregates of filaments) are distributed. As our output variable, i.e., the presence or absence of accumulation in the satellite pixel nearest to the ship measurement, was binary $(1=$ accumulations detected; $0=$ accumulations not detected), we used the logistic regression to model the relationship between predictor variables such as PC fluorescence, Chl $a$ fluorescence or turbidity and the binary response variable. Best fits of the two parameters, intercept (a) and slope (b), were found for the following equation:

$P=\frac{1}{1+e^{-(a+b X)}}$.

We used the Newton-Raphson method of iteratively finding the best fit as implemented in the NMath numerical libraries (http://www.centerspace.net/). As in linear regression, we were interested in finding the best model of a predictor variable to help explain the binary output. It turned out that all three predictor variables were significantly related to the detected cyanobacteria but the strongest relationship was with PC fluorescence, followed by turbidity and then by Chl $a$ fluorescence. All estimates of the goodness-of-fit (G-statistic, Pearson statistic, Hosmer-Lemeshow statistic) showed significant relationships at the 0.05 level of significance. The parameters of the logistic regression were not constant from transect to transect. That was expected as the voltages were not calibrated in absolute concentrations, but it was mostly due to the variable relationships between surface-detected accumulations and the vertical distribution of cyanobacteria in the water column (Groetsch et al., 2012). For a typical transect (15 July 2010) the logistic regression parameters with PC fluorescence were: intercept 2.79 (0.05 confidence interval to 2.61-2.96) and slope 0.083 (0.05 confidence interval 0.076-0.090). Probability curves of the accumulations for the full ranges of predictor variables (Fig. 9) show that detected cyanobacteria accumulations were most sensitive to PC fluorescence and somewhat less to turbidity. The effect of Chl $a$ fluorescence had a much weaker effect and the relationship was less tight.

\subsection{Timing of the accumulations}

Figure 10 shows the monthly FCA of the months of June, July and August for the period when most accurate coverage exists (during 1998-2012). While the first accumulations often appear in June, the mean monthly FCA for June is always very low. In some years $(2002,2003,2005,2006,2008,2010$ and 2013) the July FCA is much higher than that of August whereas in other years (1998, 2007, 2011 and 2012) July and August have similar FCA. The highest FCAs were recorded in periods of warm and sunny weather. As the monthly period of compositing is too long to discover smaller temporal changes, we made 5-day composited FCA for each pixel. Analogously to the calculation of the center of gravity, we calculated the "center of timing". For each year and each pixel we estimated $G=\sum$ (day $\times$ FCA) and $F=\sum$ FCA, where day is the middle day-of-year of the 5-day period and FCA is the 5-day FCA of a pixel. The center of timing was defined as $G / F$ and represents the temporal center of the accumulations in days-of-year. For an individual pixel the annual center of timing can be quite variable. We therefore used the median for a larger area of pixels, e.g., the whole Baltic Sea or any of the nine sub-areas (Fig. 2). Figure 11a shows the median of the center of timing for the whole Baltic Sea 

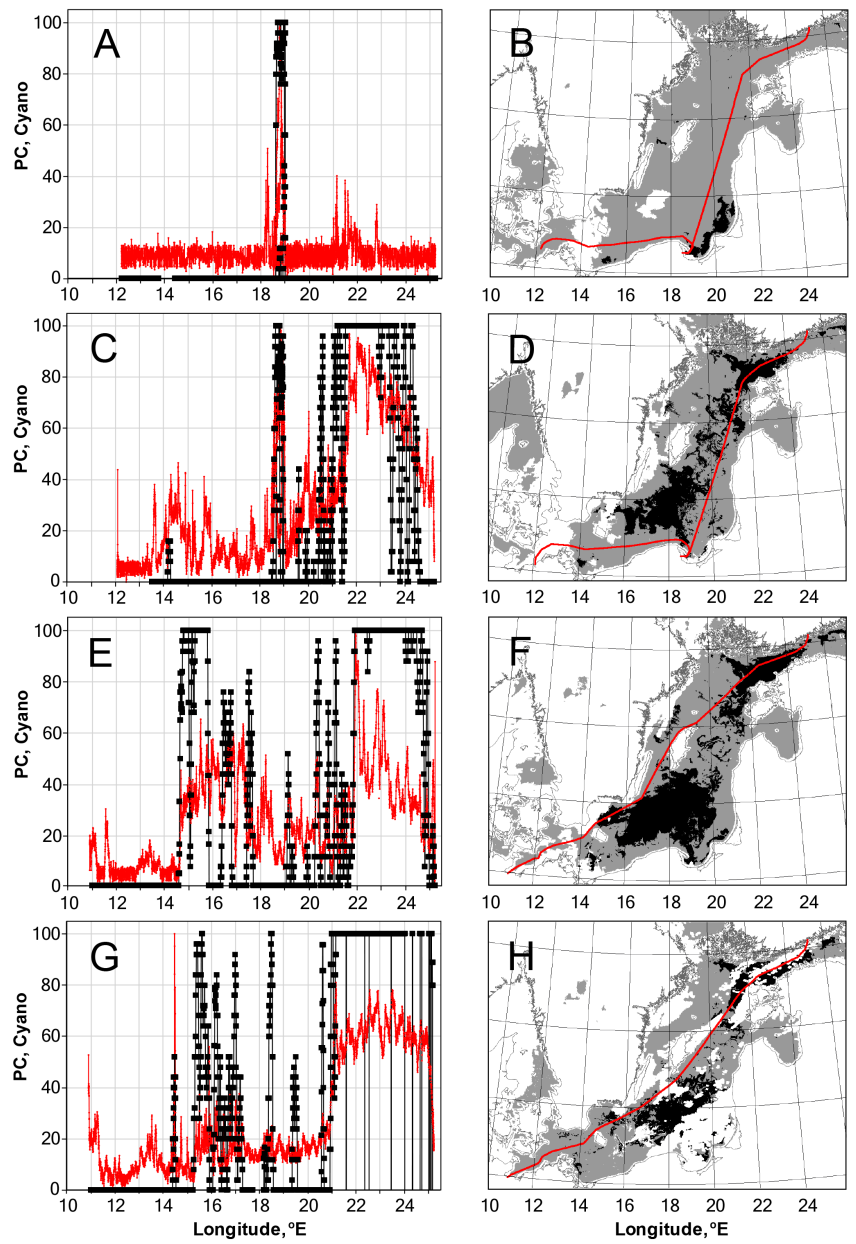

Figure 8. Comparison between ship transects of phycocyanin (PC) fluorescence (left panels) and satellite detection of cyanobacteria accumulations (right panels) in July 2010. Along-transect PC fluorescence (red, relative scale from $0-100$ ) is shown together with the corresponding satellite mean score for accumulations in the $5 \times 5$ pixel window centered at the nearest pixel (black squares). Satellite maps show detected accumulations (black), valid areas with no detected accumulations (gray), missing data due to clouds (white) and the ship track (red line). (A, B) 3 July; (C, D) 10 July; (D, F) 12 July; (G, H) 20 July.

during 1979-2013. In spite of the strong interannual variability a significant $(P<0.001)$ trend towards earlier occurrence can be detected. The mean trend is approximately 0.6 days per year or 6 days per decade. This means that over the 35-year observation period the center of timing in the Baltic Sea has become 20 days earlier. The mean center of timing has therefore changed from approximately 8 August (day-ofyear 220) to 19 July (day-of-year 200). The trend in center of timing can be estimated also in each of the nine sub-areas, but the interpretation is less obvious as some years may not have any accumulations. The Northern Baltic Proper and the Eastern Gotland Basin (sub-areas 4 and 6) are the only subareas with at least some accumulations for the whole 35-year

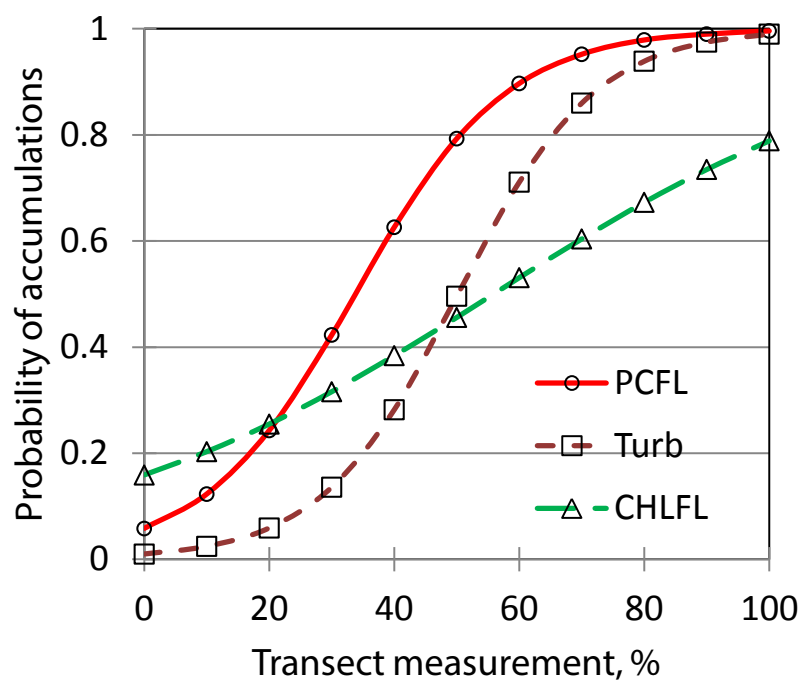

Figure 9. Probability of surface cyanobacteria accumulations estimated with the logistic regression as a function of phycocyanin fluorescence (PCFL), turbidity (Turb) and Chl $a$ fluorescence (CHLFL) at approximately $5 \mathrm{~m}$ depth. The values of PCFL, Turb and CHLFL are normalized to a scale from $0-100$.

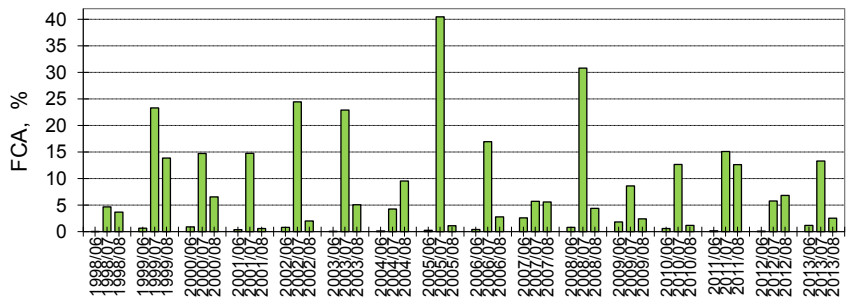

Figure 10. Monthly mean FCA in June, July and August for the Baltic Sea based on ocean color satellite data in 1998-2013.

period and the trend towards earlier occurrence is also visible there (Fig. 11b). The interannual variations in the timing of the accumulations in individual areas are typically coherent over the whole Baltic Sea. Accumulations in the Bothnian Sea typically occur in August, and are on average about 20 days later than in the Northern Baltic Proper (Fig. 11b). No accumulations were detected in the Bothnian Sea during 1991-1996 but they have occurred annually after that.

\subsection{Time series of the mean July-August FCA}

The daily data sets of the turbid and valid classes were composited into annual two month (July-August) counts, and the respective cyanobacteria fractions (FCA) were calculated (Table 2 and Fig. 12). It appears that the mean FCA of the Baltic Sea is well correlated $\left(R^{2}=0.55\right)$ with the total area $\left(\mathrm{TA}, \mathrm{km}^{2}\right)$ of the accumulations. The average FCA for the second half of the time series (1997-2013, 13.8\%) was significantly $(P<0.01)$ higher than that during the first half $(1979-1996,8.6 \%)$ but that does not seem to represent a temporal trend. Instead, it is suggestive of a wave-like pattern 

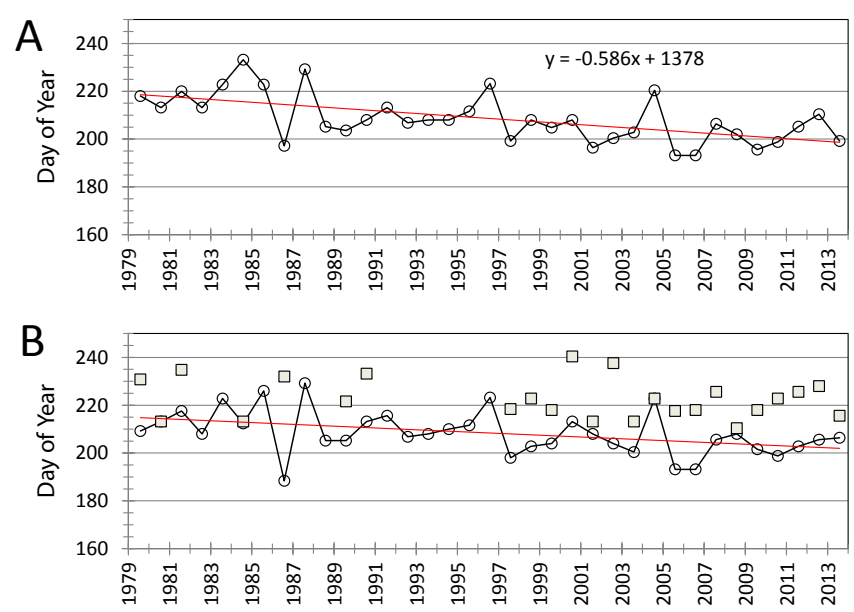

Figure 11. Temporal changes in the center of timing of the occurrence of cyanobacteria accumulations (median of the area). (A) the whole Baltic Sea; (B) Northern Baltic Proper (circles connected by solid black line) and Bothnian Sea (gray squares). Red line is the estimated linear regression for the whole Baltic (A) or the Northern Baltic Proper (B). 1 July is day-of-year 182 (day-of-year 183 on leap years), day-of-year 200 is 18 July (19 July on leap year).

with frequent cyanobacteria accumulations in the late 1970s and early 1980s (FCA 5-10\%), low FCA or almost no accumulations during 1985-1990, and an increase starting in 1991. Another short minimum in FCA occurred in 19951996. A significant increase started again in 1997. It should be noticed that the significant increase in FCA started one year before the start of the availability of ocean color data in 1998 and that the high FCA during the years of available high-quality data is coincidental. All-time maxima in FCA and TA occurred in 2005 and 2008 and after 2008 the trend has been downward.

\subsection{Spatial patterns in FCA}

The spatial patterns in the annual July-August FCA (Fig. 13) show strong year-to-year variability in the locations of areas with high occurrence of accumulations. For example, in 2001 and 2006 high FCA was predominantly in the southwestern Baltic Sea whereas in 2007 FCA was low in the southwestern Baltic and high in the northeastern Baltic and the Gulf of Finland. These patterns can be objectively decomposed into empirical orthogonal functions (EOF) and their loadings. The dominant EOF show the dominant distribution patterns. The most dominant mode (EOF 1) explains $38 \%$ of the total variability and has high FCA in the eastern Baltic from north to south (Fig. 14a). The second mode (EOF 2) explains $18 \%$ of the total variability and has high FCA in the southwestern Baltic (Fig. 14b). Time series of the loadings of EOF (Fig. 14c) show years when these modes were either high or low. For example, southwestern accumulations were dominant (high EOF 2) in the years 2001 and 2006 and also in 2013. High values of EOF 1 (years 1999, 2005 and 2008) show high FCA along the eastern side of the Baltic Sea. These years also coincide with years of overall high FCA in the Baltic Sea (Fig. 12). Low values of the respective EOF loadings show the opposite patterns. For example, years 2003 and 2011 with low EOF 2 loadings have low FCA in the southwestern Baltic.

\section{Discussion}

\subsection{Methods of detecting cyanobacteria accumulations}

Surface accumulations of cyanobacteria are a conspicuous natural phenomenon in the Baltic Sea and are commonly observed from ships, aircraft and earth-sensing satellites. The earliest report of a surface accumulation identified as Nodularia in the Baltic seems to be from the summer of 1901, observed from a ship in the southern Baltic (Apstein, 1902), i.e., over 110 years ago. The first scientific satellite observation of a Nodularia accumulation was made in 1973 (Öström, 1976), possibly the very first application of satellite technology in biological oceanography. While anecdotal observations of cyanobacteria accumulations in the Baltic are common, quantitative time series are difficult to obtain. For example, the sampling frequencies of official oceanographic monitoring programs are typically too coarse in space and time to create reliable time series (e.g., Finni et al., 2001). Satellite sensors often provide visually stunning imagery but quantitative time series are hard to compile. Moreover, time series generated from one satellite sensor are not necessarily compatible with time series generated from another satellite sensor (e.g., Gregg et al., 2009). The lifetime of a typical satellite sensor is too short to collect quantitative interannual time series of sufficient length. We therefore used multiple satellite sensors and included both the old and new data sets.

Several algorithms using spectral bands in the red and the "red edge" portion of the near-infrared spectrum can be applied to MERIS data for the detection of cyanobacteria, e.g., the fluorescent line height (FLH; Gower et al., 1999), the maximum chlorophyll index (MCI; Gower et al., 2006), the cyanobacteria index (CI; Wynne et al., 2008) and the maximum peak height (MPH; Matthews et al., 2012). Hyperspectral sensors, e.g., HICO (Lucke et al., 2011), have even more potential in creating algorithms that are specific to particular features in the absorption, fluorescence or backscattering spectra of cyanobacteria. While these algorithms are potentially more accurate for separating cyanobacteria from other types of algae and other substances in the water, they are specific to the band sets of particular sensors (e.g., MERIS). Therefore those algorithms cannot be extended backwards to the early sensors. We therefore did not attempt to use these spectral methods of detecting cyanobacteria. An important factor in the application of these spectral algorithms is that the optical characteristics of cyanobacteria accumulations are 


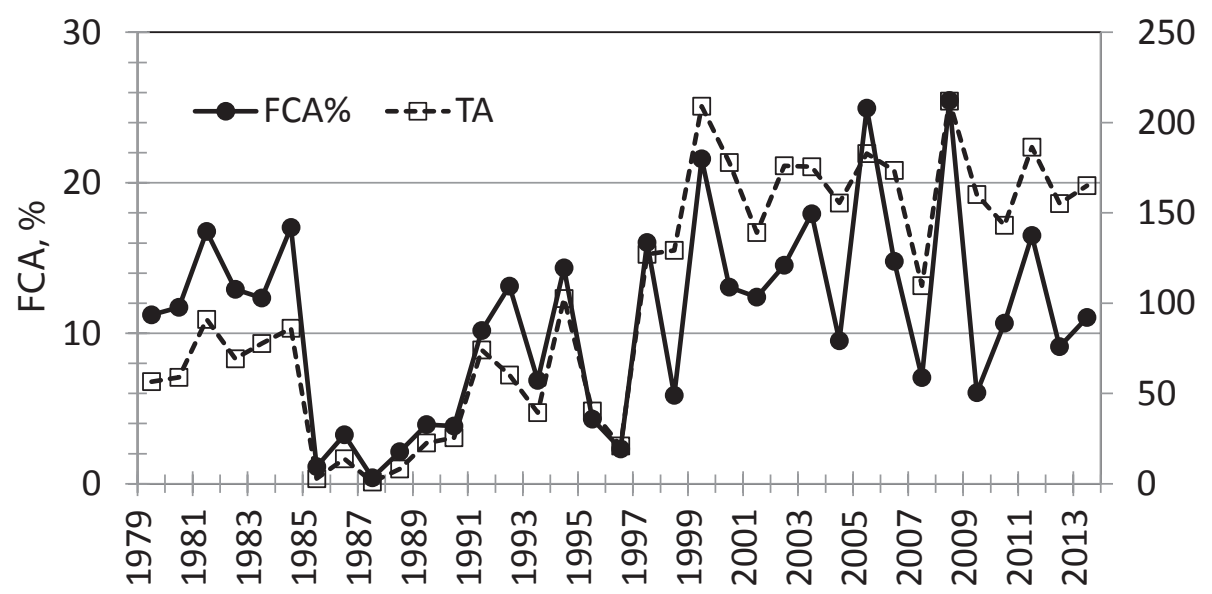

Figure 12. Mean FCA (\%) for the July-August period in the Baltic Sea (solid black circle, left axis) and the corresponding total area (TA, $\mathrm{km}^{2}$; rectangle, dashed line) of the accumulations (corresponding numerical data in Table 2).

very sensitive to their vertical distribution. As water absorbs strongly in the red part of the spectrum, it makes a drastic difference to the reflectance spectrum if the accumulations extend slightly above the water surface (i.e., surface scum) or are submerged just under the air-water interface. A sudden increase in wind speed can quickly change the vertical structure of the accumulations, mix the accumulations in the upper few meters and drastically change the output of algorithms that are too sensitive to the vertical distribution of the accumulations. For example, the normalized vegetation index (NDVI) that is being used to detect land vegetation can be applied to the Baltic AVHRR data (Kahru et al., 1993) but it detects only the surface scum that can disappear and reappear within a day depending on the wind speed. Multiand hyper-spectral algorithms are not applicable to old sensors like AVHRR with only one band in the visible part of the spectrum. In order to create a series as long as possible using different kinds of satellite sensors including those with low signal-to-noise ratio, we opted to use simple, generic algorithms that are sensitive to brightness in the red part of the spectrum.

It is technically challenging to create a consistent time series that combines data from multiple satellite sensors over a long time period. We have here provided methods for linking estimates of FCA from the old AVHRR and CZCS sensors with those from the new ocean color sensors, and created a 35-year long time series of the frequency of cyanobacteria accumulations in the Baltic Sea. While our satellite data are limited to cloud-free periods and detect the presence of cyanobacteria only by their surface signature, the relative temporal consistency of the accumulations and the large number of satellite measurements (Table 2) gives us confidence in the interannual time series. It is difficult to compare our interannual time series with the results from the traditional monitoring programs which typically sample a few fixed stations once per month. A single monthly sam- ple can easily miss the high cyanobacteria concentration in a plume floating nearby (e.g., Finni et al., 2001) and the mean error for the more stable chlorophyll $a$ concentration has been estimated to be $\sim 100 \%$ due to temporal aliasing and another $\sim 100 \%$ due spatial heterogeneity (Kahru and Aitsam, 1985). Higher temporal and spatial frequency is provided by programs like Algaline (Rantajärvi, 2003) using ships of opportunity. However, the Chl $a$ in vivo fluorescence that is often used as a measure of phytoplankton biomass is a poor measure of the abundance of cyanobacteria as most of the cyanobacterial Chl $a$ is located in the non-fluorescing photosystem I (Seppälä et al., 2007 and references therein). It was also confirmed in this work that $\mathrm{Chl} a$ florescence was a worse predictor for detecting cyanobacteria accumulations than either phycocyanin fluorescence or turbidity (Fig. 9). The Algaline program also collects a small number of discrete water samples that are used to measure $\mathrm{Chl} a$ from extracts using standard methods. The extracted Chl $a$ is much better correlated with cyanobacteria abundance (Seppälä et al., 2007) than Chl $a$ fluorescence. Preliminary comparison between $\mathrm{Chl} a$ values extracted from discrete water samples provided by S. Kaitala (Finnish Environment Institute, SYKE) and FCA along the ship tracks where samples were collected showed quite similar interannual patterns. The mean chlorophyll $a$ concentration of samples collected during July-August in the Eastern Gotland Basin had a coherent pattern with FCA $\left(R^{2}=0.48\right.$, Fig. 15$)$ but much lower variability (mean $=3.8 \mathrm{mg} \mathrm{m}^{-3}$, coefficient of variation $=0.22$ ). The corresponding time series of FCA had a coefficient of variation that was 4-5 times higher (1.03 for 1995-2012 and 1.34 for 1979-2013). This difference in variability was expected as Chl $a$ integrates all phytoplankton whereas FCA is a much more sensitive parameter as the detection of surface accumulations requires very high concentrations of cyanobacteria (primarily Nodularia) near the surface. An analysis of the environmental conditions explaining 


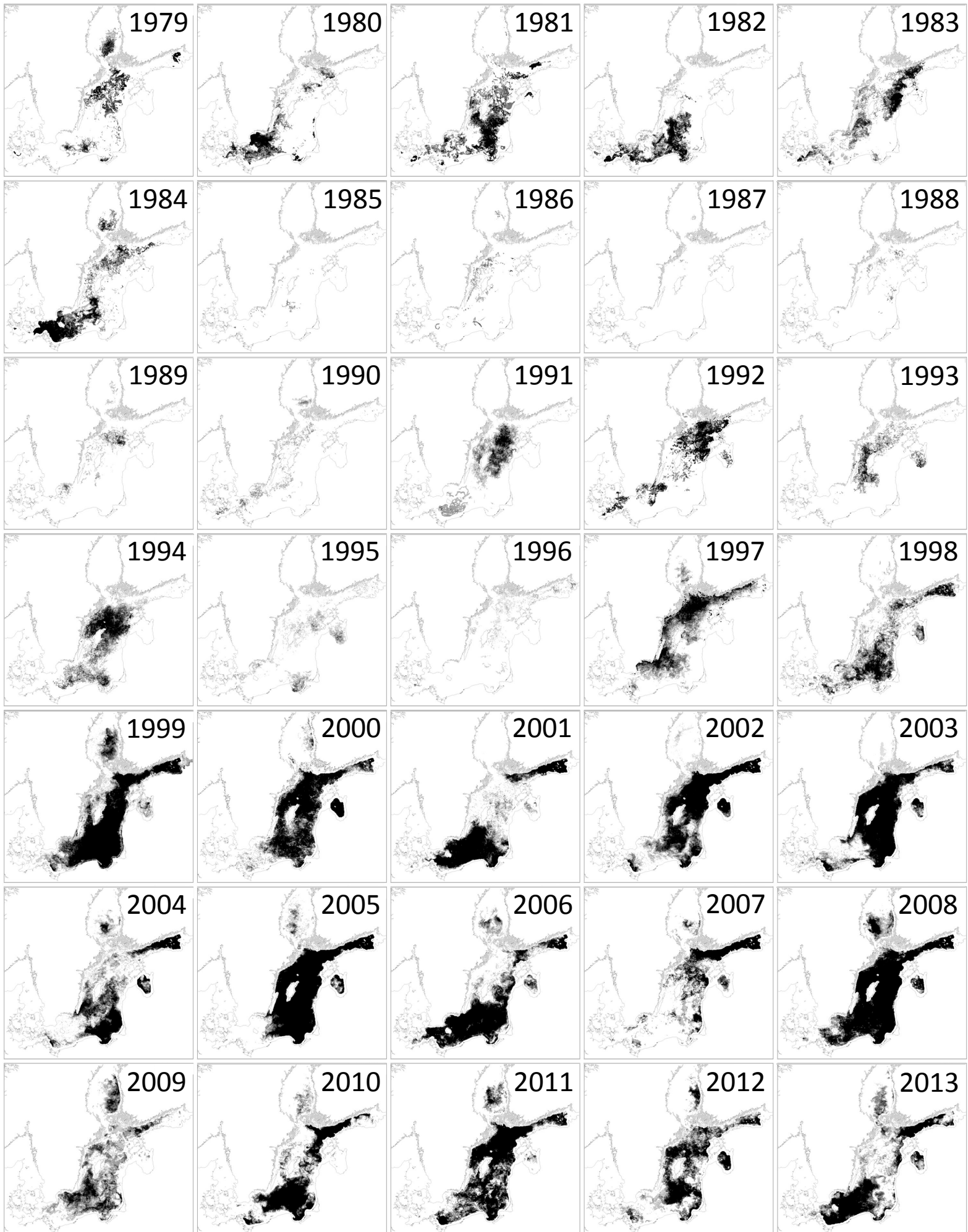

Figure 13. Maps of the mean July-August FCA in the Baltic Sea, 1979-2013. Gray-scale from light to dark corresponds to increasing FCA. 

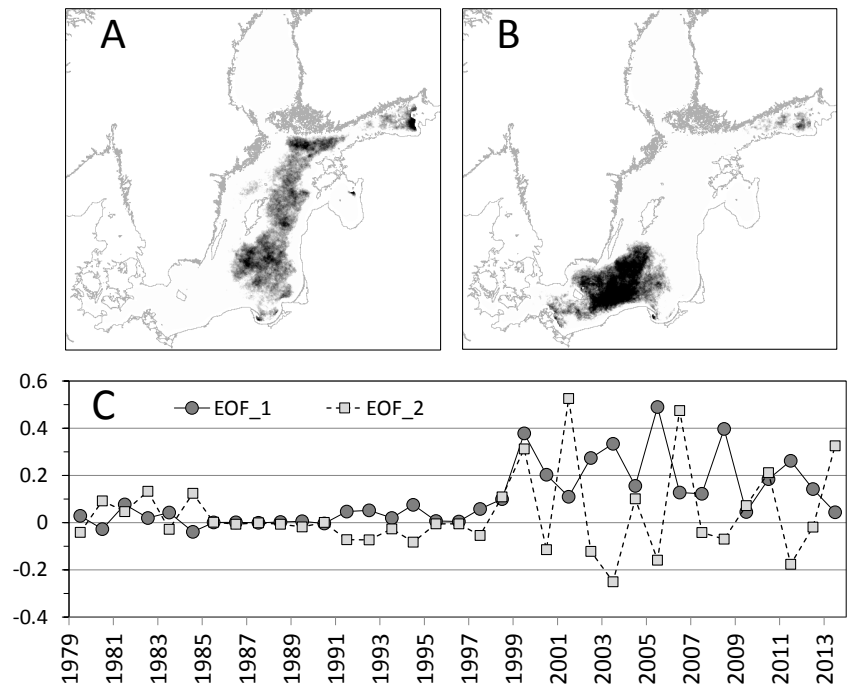

Figure 14. Dominant distribution patterns, i.e., empirical orthogonal functions EOF 1 (A) and EOF 2 (B) of the annual July-August FCA in the Baltic Sea for 1979-2013 and their temporal loadings (C).

the interannual patterns in FCA (cf. Kahru et al., 2007) is planned for the future. Future work should also compare this FCA data set with the more advanced multi- and hyperspectral methods like the maximum peak height (Matthews et al., 2012).

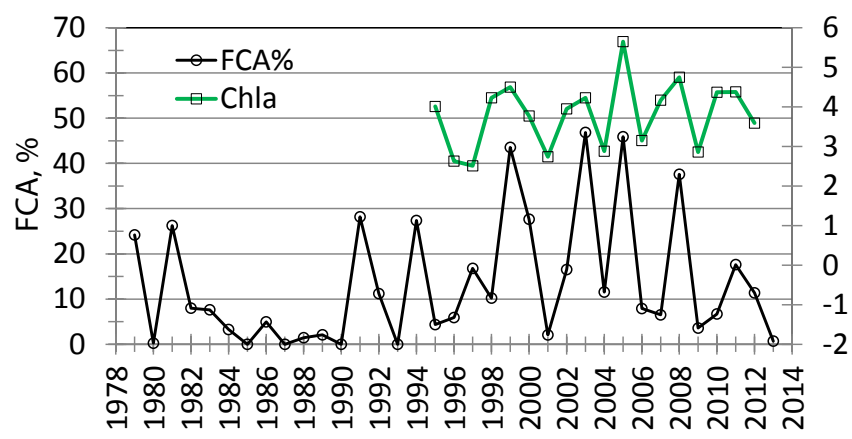

Figure 15. Time series from along Algaline ship transects in the Eastern Gotland basin during July-August: mean extracted chlorophyll $a\left(\mathrm{mg} \mathrm{m}^{-1}\right)$ at approximately $5 \mathrm{~m}$ depth (green line, right axis) and the corresponding frequency of cyanobacteria accumulations (black line, left axis).

\section{Conclusions}

- A 35-year time series of quantitative observations of summer cyanobacterial surface accumulations in the Baltic Sea was compiled using data from multiple satellite sensors.
- The fraction of cyanobacterial accumulations (FCA) for the Baltic Sea during the July-August period varied between 0 and about $25 \%$. Estimates of FCA using different ocean color sensors were similar with the median absolute differences about $0.5 \%$ for MODISAqua, MODIS-Terra and VIIRS and about $1 \%$ for SeaWiFS. The fraction of cyanobacteria accumulations estimates using AVHRR were transformed to correspond to the estimates by the ocean color sensors.

- No surface accumulations were observed in the Bothnian Bay.

- Surface accumulations were significantly more common in the second half of the observation period, but the increase was not monotonic, and interannual variability was large.

- The period of cyanobacterial accumulations occurred progressively earlier in the summer, by about 0.6 days per year, or 20 days over 35 years.

Acknowledgements. Financial support was provided to R. Elmgren by the Swedish Research Council Formas and Stockholm University's Baltic Ecosystem Adaptive Management Program. Additional funding to M. Kahru was provided by the Finnish Academy through a grant to T. Tamminen. Satellite ocean color data were provided by the NASA Ocean Color Processing Group. AVHRR data were provided by Dundee Satellite Receiving Station. The authors thank S. Kaitala for providing Algaline extracted chlorophyll $a$ data, J. Seppälä for providing the Algaline transect data, T. Tamminen and Oleg Savchuk for useful discussions and Andrew Brooks for AVHRR data conversion.

Edited by: B. A. Bergamaschi

\section{References}

Apstein, C.: Das Plankton der Ostsee (Holsatia Expedition 1901). Abhandl. Deutschen Seefischerei - Vereins. VII, 103-129, 1902 (In German).

Bianchi, T. S., Engelhaupt, E., Westman, P., Andren, T., Rolff, C., and Elmgren, R.: Cyanobacterial blooms in the Baltic Sea: natural or human-induced?, Limnol. Oceanogr., 45, 716-726, 2000.

Finni, T., Kononen, K., Olsonen, R., and Wallström, K.: The history of cyanobacterial blooms in the Baltic Sea, Ambio, 30, 172-178, 2001.

Gower, J., Hu, C., Borstad, G., and King, S.: Ocean color satellites show extensive lines of floating Sargassum in the Gulf of Mexico, IEEE Trans. Geoscience Remote Sens., 44, 3619-3625, 2006.

Gower, J. F. R., Doerffer, R., and Borstad, G.: Interpretation of the $685 \mathrm{~nm}$ peak in water-leaving radiance spectra in terms of fluorescence, absorption and scattering, and its observation by MERIS Int. J. Remote Sens., 20, 1771-1786, 1999.

Gregg, W. W., Casey, N. W., O'Reilly, J. E., and Esaias, W. E.: An empirical approach to ocean color data: Reducing bias and the 
need for post-launch radiometric re-calibration, Remote Sens. Environ., 113, 1598-1612, 2009.

Groom, S. B. and Holligan, P. M.: Remote sensing of coccolithophore blooms, Adv. Space Res., 7, 73-78, 1987.

Hajdu, S., Höglander, H., and Larsson, U.: Phytoplankton vertical distributions and composition in Baltic Sea cyanobacterial blooms, Harmful Algae, 6, 187-205, 2007.

Horstmann, U.: Eutrophication and mass occurrence of blue-green algae in the Baltic, Merentutkimuslait. Julk./Havsforskningsinst Skr., 239, 83-90, 1975.

Horstmann, U.: Distribution patterns of temperature and water colour in the Baltic Sea as recorded in satellite images: indicators of plankton growth. Berichte Institut für Meereskunde Universität Kiel, 106, 1-147, 1983.

Hovis, W. A., Clark, D. K., Anderson, F., Austin, R. W., Wilson, W. H., Baker, E. T., Ball, D., Gordon, H. R., Mueller, J. L., El-Sayed, S., Sturm, B., Wrigley, R. C., and Yentsch, C. S.: NIMBUS-7 Coastal Zone Color Scanner: System description and initial imagery, Science, 210, 60-63, 1980.

$\mathrm{Hu}, \mathrm{C}$., Feng, L., and Lee, Z.: Uncertainties of SeaWiFS and MODIS remote sensing reflectance: Implications from clear water measurements, Rem. Sens. Environ., 133, 168-182, 2013.

Kahru, M.: Using satellites to monitor large-scale environmental change: A case study of cyanobacteria blooms in the Baltic Sea, in: Monitoring algal blooms: New techniques for detecting largescale environmental change, edited by: Kahru, M. and Brown, C. W., Springer Verlag, Berlin-Heidelberg-New York, 43-61, 1997.

Kahru, M. and Aitsam, A.: Chlorophyll variability in the Baltic Sea: a pitfall for monitoring, J. Cons. int. Explor. Mer., 42, 111-115, 1985.

Kahru, M., Leppänen, J.-M. and Rud, O.: Cyanobacterial blooms cause heating of the sea surface, Mar. Ecol. Prog. Ser., 101, 1-7, 1993.

Kahru, M., Horstmann, U., and Rud, O.: Satellite detection of increased cyanobacteria blooms in the Baltic Sea: Natural fluctuation or ecosystem change?, Ambio, 23, 469-472, 1994.

Kahru, M., Leppänen, J.-M., Rud, O., and Savchuk, O. P.: Cyanobacteria blooms in the Gulf of Finland triggered by saltwater inflow into the Baltic Sea, Mar. Ecol. Prog. Ser., 207, 13-18, 2000.

Kahru, M., Savchuk, O. P., and Elmgren, R.: Satellite measurements of cyanobacterial bloom frequency in the Baltic Sea: Interannual and spatial variability, Mar. Ecol. Prog. Ser, 343, 15-23, 2007.

Kidwell, K. B.: NOAA Polar Orbiter Data Users Guide (TIROSN, NOAA-6, NOAA-7, NOAA-8, NOAA-9, NOAA-10, NOAA11, NOAA-12, NOAA-14), Washington, DC, Natl. Oc. Atmos. Administrat., 1995.

Kononen, K.: Dynamics of the toxic cyanobacterial blooms in the Baltic Sea, Finnish. Mar. Res., 261, 3-36, 1992.

Kutser, T.: Quantitative detection of chlorophyll in cyanobacterial blooms by satellite remote sensing, Limnol. Oceanogr., 49, 2179-2189, 2004.

Larsson, U., Hajdu, S., Walve, J., and Elmgren, R.: Estimating Baltic nitrogen fixation from the summer increase in upper mixed layer total nitrogen, Limnol.Oceanogr., 46, 811-820, 2001.
Liblik, T. and Lips, U.: Spreading of suspended matter in a shallow sea area influenced by dredging activities and variable atmospheric forcing: results of in situ measurements, J. Coast. Res., UK86, 783-788, 2011.

Lucke, R. L., Corson, M., McGlothlin, N. R., Butcher, S. D., Wood, D. L., Korwan, D. R., Li, R. R., Snyder, W. A., Davis, C. O., and Chen, D. T.: Hyperspectral Imager for the Coastal Ocean: instrument description and first images, Appl. Opt., 50, 11, 1501-1516, 2011.

Matthews, M. W., Bernard, S., and Robertson, L.: An algorithm for detecting trophic status (chlorophyll $a$ ), cyanobacterialdominance, surface scums and floating vegetation in inland and coastal waters, Remote Sens. Environ., vol. 124, 637-652, 2012.

Öström, B.: Fertilization of the Baltic by nitrogen-fixation in the blue-green alga Nodularia spumigena, Remote Sens. Environ., 4, 305-310, 1976.

Rantajärvi, E.: Alg@line in 2003: 10 years of innovative plankton monitoring and research and operational information service in the Baltic Sea. Meri - Report Series of the Finnish Institute of Marine Research, 48, 58 pp., 2003.

Rolff, C., Almesjö, L., and Elmgren, R.: Nitrogen fixation and the abundance of the diazotrophic cyanobacterium Aphanizomenon sp. in the Baltic Proper, Mar. Ecol. Prog. Ser., 332, 107-118, 2007.

Seppälä, J., Ylöstalo, P., Kaitala, S., Hällfors, S., Raateoja, M., and Maunula, P.: Ship-of-opportunity based phycocyanin fluorescence monitoring of the filamentous cyanobacteria bloom dynamics in the Baltic Sea, Estuarine, Coast. Shelf Sci., 73, 489500, 2007.

Simis, S. G. H. and Olsson, J.: Unattended processing of shipborne hyperspectral reflectance measurements, Remote Sens. Environ., 135, 202-212, 2013.

Stumpf, R. P. and Frayer, M. L.: Use of AVHRR imagery to examine long-term trends in water clarity in coastal estuaries: Example in Florida Bay. In: Monitoring algal blooms: New techniques for detecting large-scale environmental change, edited by: Kahru, M. and Brown, C. W., Springer Verlag, Berlin-Heidelberg-New York, 1-24, 1997.

Volten, A. H., Haan, J. F. D., Hovenier, J. W., Schreurs, R., Vassen, W., Dekker, A. G., Hoogenboom, J., Charlton, F., and Wouts, R.: Laboratory Measurements of Angular Distributions of Light Scattered by Phytoplankton and Silt, Limnol. Oceanogr., 43, 1180-1197, 1998.

Walsby, A. E.: Gas vesicles, Microbiol. Rev., 58, 94-144, 1994.

Wasmund, N.: Occurrence of cyanobacterial blooms in the Baltic Sea in relation to environmental conditions, Int. Revue Gesamten Hydrobiol., 82, 169-184, 1997.

Wynne, T. T., Stumpf, R. P., Tomlinson, M. C., Warner, R. A., Tester, P. A., Dyble, J., and Fahnenstiel, G. L.: Relating spectral shape to cyanobacterial blooms in the Laurentian Great Lakes, Int. J. Remote Sens., 29, 3665-3672, 2008. 